\title{
Crowdsourcing virtual summer research opportunities to support minorities in microbiology
}

\author{
Summer research programmes are renowned for encouraging underrepresented minorities (URMs) to pursue \\ STEM careers, but COVID-19 left many students in the United States unable to participate. We created the \\ National Summer Undergraduate Research Project to matchmake students with mentors, enabling 250 URM \\ students to do summer research.
}

\section{Michael D. L. Johnson, David A. Baltrus and Jennifer Gardy}

$\mathrm{t}$ is no secret that underrepresented minorities (URMs) who are Latinx, Black, Indigenous and people of colour (BIPOC) face multiple hurdles to achieve success in science, technology, engineering and mathematics (STEM). Challenges such as a lack of accessibility, opportunity and representation begin in early education and are pervasive through to, and including, being an independent group leader ${ }^{1-3}$. For those that eventually transition into careers in science, the first research experience serves as a crucial launching point.

Fortunately, there are numerous summer research programmes at research-focused universities, including the Minimizing Health Disparities (MHD) programme at the University of Arizona, partnerships between primarily undergraduate institutions and research-focused institutions such as the National Institutes of Health (NIH)-funded Building Infrastructure Leading to Diversity programme, and more national, year-long (or more) programmes such as the United States Department of Education's Federal TRIO Programs-funded McNair Scholars programme, or the NIH-funded Maximizing Access to Research Careers (MARC) programme. These programmes provide access, training and financial assistance to those who might not have the opportunity to pursue science at their home institution. Research arising from these programmes is highlighted nationally when thousands of URMs (and first-generation college students) descend on undergraduate-focused conferences such as the Annual Biomedical Research Conference for Minority Students (ABRCMS) and the Society for Advancement of Chicanos/ Hispanics and Native Americans in Science (SACNAS) to present their findings.

The Johnson laboratory has witnessed students flourish during these programmes first-hand, as one MHD student continued into graduate school at Duke University, and another student continued from the MARC programme to Massachusetts Institute of Technology. Both students presented at ABRCMS and/or SACNAS. However, a McNair scholar, whom Johnson met at ABRCMS, was supposed to be in the Johnson laboratory in the summer of 2020 but was unable to travel due to COVID-19. While the laboratory was able to set up a collaborative virtual research project so that the McNair scholar didn't miss out, the question arose as to how many URMs were unable to attend a summer programme and were therefore missing out on that precious first experience of research. Missing out on a summer research programme could delay graduate education or compromise it altogether.

It became clear that the effects of COVID-19 on URM STEM education, and diversity in microbiology, would be catastrophic.

As more and more limitations were placed on what laboratories could do in person due to the spread of SARS-CoV-2, and racial tensions were flaring, we (Drs Johnson, Baltrus and Gardy) met in early June 2020 and founded the National Summer Undergraduate Research Program (NSURP). NSURP is a virtual matchmaking programme for research experiences designed to help the most disadvantaged students access this vital step towards a career in STEM. We did not know what to expect in terms of support for NSURP, so we decided that the group of undergraduates we would concentrate on were BIPOC, and that we would focus solely on our own field of microbiology. We uploaded Google forms for NSURP mentees and mentors to complete, which were outputted onto a Google sheet, and launched a website to host all of the content ${ }^{4}$. The mentee form asked for ethnicity, first-generation status, which (if any) summer research programme the mentee was unable to attend, a list of interests, how many hours the mentee could devote to a project, year of study, major, a personal statement and their time zone. Mentors who ranged from professor-level scientists through to graduate trainees and staff scientists in the laboratory were asked to provide a description of research in their laboratory, research keywords, a virtual project name, how many students they could mentor in one summer and their time zone.

We decided that the NSURP programme would run for eight weeks from 22 June 2020 to 14 August 2020, and launched the website for mentor and mentee sign-up on 15 June 2020. This is where crowdsourcing and word of mouth would be put to the test as we hoped opportunity, the desire to help and the need of mentees would collide. We advertised NSURP through our personal Twitter accounts and e-mailed programme directors who had programmes with students who could not attend. By Juneteenth (19 June 2020; the date commemorating the end of slavery in 1865 in the United States) at 11:59 PM, we had more than 100 mentors from around the world who represented around 150 slots, and over 250 undergraduates, of whom more than 75 were BIPOC. The additional registered mentors allowed NSURP to expand and offer slots to over 70 Latinx students. On 22 June 2020, we sent individualized e-mails to match the undergraduates and mentors. As the number of applications and mentors continued to increase, on 14 July 2020 we released a second wave of pairings to match an additional 100 BIPOC and Latinx undergraduates to 50 more mentors, for a 
Table 1 | Demographic patterns of the 2020 NSURP cohort

\begin{tabular}{|ll}
\hline Total students matched in NSURP & 250 \\
\hline First cohort & 137 \\
\hline Second cohort & 113 \\
\hline Could not attend summer programme & $30.4 \%$ \\
\hline First-generation college student & $54.0 \%$ \\
\hline Year in higher education & \\
\hline Freshman & $5.6 \%$ \\
\hline Sophomore & $22.4 \%$ \\
\hline Junior & $33.6 \%$ \\
\hline Senior & $37.6 \%$ \\
\hline Other & $0.8 \%$ \\
\hline Ethnicity & \\
\hline Black/African American & 134 \\
\hline Native American & 9 \\
\hline Latinx & 111 \\
\hline Type of home institution & \\
\hline Historically Black college or university & $14.0 \%$ \\
\hline Hispanic-serving institution & $24.4 \%$ \\
\hline American Indian- and Alaska Native-serving institutions & $2.8 \%$ \\
\hline Land-grant institution & $27.2 \%$ \\
\hline Community college & $1.2 \%$ \\
\hline Some & \\
\hline
\end{tabular}

aSome participants classify as biracial.

programme total of 250 students and over 150 mentors (Table 1 ).

We must acknowledge that upon learning about this initiative, Johnson's department head Dr Janko Nikolich-Žugich - who has been adamant about supporting his URM faculty (including Johnson) and departmental diversity training, and has provided funding for our departmental diversity and inclusion committee 'forbade' him to go further without lending the assistance of his administrator, Ms Lori Wieland, who was a godsend. To be clear, enabling with actions instead of words alone is how you support URMs in STEM.

Once matches were made, each NSURP student-mentor pair discussed the virtual project so that the scope of the project could evolve through mentee-mentor interactions. Types of projects included analysing microbiome or genome datasets, literature reviews, citizen science and more. Students and mentors both signed participation contracts and were given resources. Mentors had access to anti-racist, remote mentoring and diversity training resources, and mentees received online professional development resources. All students who signed up (over 500) had access to the BIPOC weekly seminar series, regardless of their matched status. Seminars highlighted both new and established
BIPOC investigators and covered a wide range of topics: from science, professional development and ethics, to dealing with issues of being a URM in STEM ${ }^{5}$. These talks were uploaded to the NSURP website afterwards as a public resource with transcriptions so that those who could not attend live, or were hearing impaired, could benefit.

In addition to the matched mentees receiving online microbial training and career mentorship, we would like to thank everyone that stepped up to help in any way they could, including Manu Prakesh who provided foldscopes, which are foldable, paper microscopes for mentees to use in inspiring science in their community ${ }^{6,7}$, and the American Society of Microbiology, who waived membership fees so that mentees could access all of the online conference content for the rest of the year (including MICROBE 2020). Additional sponsors and patrons rose to the occasion to help fund awards for an essay contest inspired by the late Congressman John Lewis regarding the 'good kind of trouble', awards for other presentations and some administrative costs.

At the conclusion of the eight-week programme, NSURP students gave virtual presentations which are currently available on the NSURP website ${ }^{4}$. The format was for students to make a poster, slide show or other presentation in consultation with their mentor, and to be creative. Presentations formats included (but were not limited to) written reports, voiceovers or music accompanying slide presentations, infographics, posters and science parody music videos. Over 160 presentations were submitted within three weeks of the programme's end date, with some projects still in progress as some students continued working with their mentors. We awarded 36 honourable mentions and 15 presentation winners. Many NSURP mentees presented work from their project in intra- and inter-institutional mini symposiums organized by mentors and have also thus far been successful in having their abstracts accepted in national meetings.

A major goal of this pilot programme was to provide research experience for students who were not able to attend their summer programme. We were successful in this goal in that NSURP provided a research experience for 76 students who fell into this category (Table 1). First-generation college students accounted for $54 \%$ of the NSURP mentees, and almost $40 \%$ were from minority-serving institutions (taking into account that some institutions fit into multiple categories) (Table 1). It is our hope that the guidance students received through NSURP will help them to make more informed decisions on pursuing graduate education, compared with those who did not participate in a summer research programme. Further, we hope that NSURP students will be more likely to seek a graduate degree and do so sooner than students without a summer research opportunity ${ }^{8}$. Overall, a sense of community was formed between mentees and mentor laboratories - a link that is often described as missing for URMs ${ }^{2}$. We are hopeful that many of these relationships will continue long after this summer.

As virtual learning experiences continue to mature, STEM must continue to adapt. We need to recognize that not all students can travel during the summer to engage in research, because of family obligations, finances and/or health. While the NSURP programme is not the first to match people based on their interests, it is at the forefront of doing so at this scale, and with respect to virtual research projects for underrepresented and underserved undergraduates. As such, we hope NSURP will be a template for others to follow to engage a diverse, representative set of future scientists.

${ }^{1}$ Department of Immunobiology, University 
of Arizona, Tucson, AZ, USA. ${ }^{2}$ BIO5 Institute, University of Arizona, Tucson, AZ, USA. ${ }^{3}$ Valley Fever Center for Excellence, University of Arizona, Tucson, AZ, USA. ${ }^{4}$ School of Plant Sciences, University of Arizona, Tucson, AZ, USA. ${ }^{5}$ School of Animal and Comparative Biomedical Sciences, University of Arizona, Tucson, AZ, USA. ${ }^{6}$ British Columbia Centre for Disease Control, Vancouver, British Columbia, Canada. ${ }^{7}$ Bill and Melinda Gates Foundation, Seattle, WA, USA.

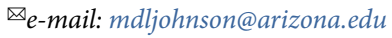

Published online: 19 October 2020

https://doi.org/10.1038/s41564-020-00807-6

References

1. Johnson, M. D. L. mSphere 4, e00599-19 (2019).

2. Estrada, M. et al. CBE Life Sci. Educ. 15, es5 (2016).

3. Gibbs, K. D., Basson, J., Xierali, I. M. \& Broniatowski, D. A. eLife 5, e21393 (2016).

4. Johnson, M. D. L., Baltrus, D. \& Gardy, J. The National Summer Undergraduate Research Project. NSURP https://nsurp.org/ (2020).

5. Kricorian, K., Seu, M., Lopez, D., Ureta, E. \& Equils, O. Int. J. STEM Educ. 7, 16 (2020).

6. Yesudhason, B. V. et al. Cell Biol. Int. 44, 1968-1980 (2020).
7. Prakash, M. \& Cybulski, J. Foldscope. Foldscope Instruments https://www.foldscope.com/ (2020).

8. Hathaway, R. S., Nagda, B. R. A. \& Gregerman, S. R. J. Coll. Stud. Dev. 43, 614-631 (2002).

Author contributions

M.D.L.J. drafted the manuscript. M.D.L.J., D.A.B. and J.G. edited the draft and prepared the final manuscript, which was approved by all co-authors.

Competing interests

The authors declare no competing interests. 